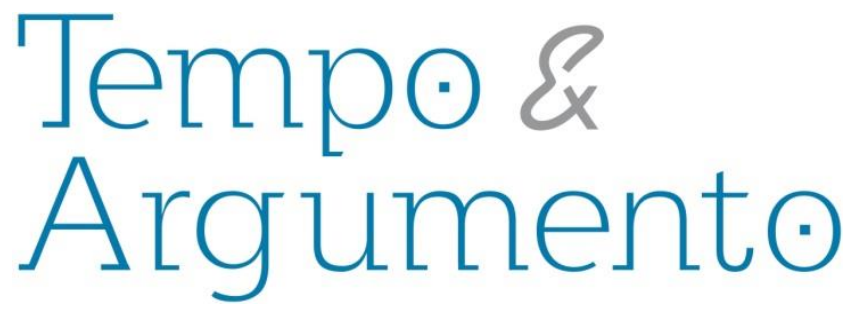

\title{
Moradia popular e eleições: o Conjunto Itararé e as disputas eleitorais em Teresina-PI (1978-1996)
}

\begin{abstract}
Resumo
O contexto do processo de ocupação e expansão das cidades brasileiras, durante o período dos governos militares, representa o interesse central da presente pesquisa, que visa a discutir o processo de ocupação populacional da cidade de Teresina (PI), bem como as estratégias de acesso à moradia, privilegiando problemáticas que envolvam histórias, memórias e as maneiras de se relacionar com o cenário urbano. Dessa forma, procuramos analisar os mecanismos de ocupação e disputas políticas existentes no Conjunto Habitacional Itararé, em um recorte que se estende de 1978 a 1996, analisando as estratégias de aproximação utilizadas por políticos junto aos moradores do conjunto e as táticas de resistência e reivindicações que estes assumiam em relação aos primeiros, tendo como cenário os pleitos eleitorais no período analisado, momento em que se pôde perceber o alinhamento ou resistência política dos moradores com os grupos que motivaram a construção do residencial. Visamos a discutir a história e memória desses moradores, destacando o seu protagonismo no cenário político-partidário da cidade em um ambiente que segregava de forma velada parte da população empobrecida de Teresina. A pesquisa recorreu ao uso da metodologia da História Oral, mais especificamente a partir de entrevistas com trajetórias de vida e uso de entrevistas temáticas, como proposto por Lucília Delgado (2010), com os moradores mais antigos do bairro e que ainda residem na região.
\end{abstract}

Palavras-chave: Eleições - Teresina (PI); Teresina (PI) - História; Conjunto Habitacional Itararé - Teresina $(\mathrm{PI})$.

\author{
Marcelo de Sousa Neto \\ Doutorado em História pela Universidade \\ Federal do Pernambuco - UFPE. Estágio \\ Pós-Doutoral em História pela \\ Universidade Federal do Piauí - UFPI. \\ Professor do Programa de Pós-Graduação \\ em História do Brasil da Universidade \\ Federal do Piauí - UFPI. Professor do \\ curso de História da Universidade \\ Estadual do Piauí - UESPI. \\ Brasil \\ casadapolvora@gmail.com
}

\section{Para citar este artigo:}

SOUSA NETO, Marcelo de. Moradia popular e eleições: o Conjunto Itararé e as disputas eleitorais em Teresina-PI (1978-1996). Revista Tempo e Argumento, Florianópolis, v. 8, n. 19, p. 209 - 235. set./dez. 2016.

\section{DOI: $10.5965 / 2175180308192016209$}

http://dx.doi.org/10.5965/2175180308192016209

\footnotetext{
${ }^{1}$ A realização desta pesquisa contou com o apoio do Conselho Nacional de Desenvolvimento Científico e Tecnológico - CNPq, por meio da Chamada MCTI/CNPQ/Universal 14/2014.
} 


\title{
Affordable housing and elections: Itararé Housing and electoral disputes in Teresina-PI (1978-1996)
}

\begin{abstract}
The context of occupation and expansion process of Brazilian cities, during the period of military governments, is the central interest of the present research, which aims to discuss the populational settlement process of Teresina $(\mathrm{PI})$, as well as strategies of access to housing, privileging matters that involving histories, memories and ways of relating to urban scenery. In this way, we intended to analyze the occupation mechanisms and political disputes existing in Itararé Housing, in a period extending from 1978 to 1996, analyzing the approach strategies used by politicians with to livers of the housing and resistance and claim tactics that they took in relation to the first ones, having as scenery the elections in the analyzed period, moment in which it's possible to notice the alignment or political resistance of the livers with the political groups that motivated the construction of the housing. We aim to discuss the history and memory of those livers, highlighting their protagonism in the political and party scenery of the city in environment that secreted covertly part of the poor population of Teresina. The research resorts to the use of Oral History Methodology, more specifically apart interviews with life trajectory and use of thematic interviews, like it's purposed by Lucília Delgado (2010), with more ancient livers of the neighborhood and still live in the region.
\end{abstract}

Keywords: Elections - Teresina (PI); Teresina (PI) - History; Conjunto Habitacional Itararé - Teresina $(\mathrm{PI})$.

\section{Introdução}

Com pouco mais de três décadas de história, o Conjunto Habitacional Itararé, localizado na região Sudeste de Teresina, tornou-se centro da vida socioeconômica de um verdadeiro conglomerado de bairros que orbitam ao seu entorno e que respondem, hoje, por uma população superior a 200 mil habitantes².

\footnotetext{
${ }^{2}$ A população de Teresina, segundo o Censo Demográfico de 2010 do IBGE, era de 814.030 habitantes.
} 
Para sua construção, o Itararé recebeu financiamento do extinto Banco Nacional da Habitação - BNH (BRASIL. BNH, 1976), sendo erguido em duas etapas: a primeira foi realizada na administração do Governador Dirceu Mendes Arcoverde (1975-1978) e a segunda etapa se configurou no governo de Lucídio Portella (1979-1983). Nessa segunda etapa, em 1979, o conjunto foi renomeado, passando a se chamar Conjunto Habitacional Dirceu Arcoverde, em homenagem ao ex-governador e senador recém-falecido.

No intuito de validar a construção desse bairro, o governo do estado justificava tal ação ao ressaltar a necessidade de resolução do déficit habitacional na capital (PIAUÍ, 1975). Contudo, a mudança dos moradores para o novo conjunto não significou a solução das demandas sociais vivenciadas pela população, que se agravaram pelas deficiências infraestruturais pós-inauguração do Conjunto, entregue a seus moradores em meio às mais precárias condições de saneamento e serviços públicos.

Com a chegada de seus primeiros moradores, a partir de julho de 1977 (ITARARÉ. O Dia, 13 jul. 1977, p.7), em meio à precariedade das condições das moradias, dos equipamentos urbanos e dos serviços públicos oferecidos no Conjunto, forjou-se no seio da população local uma forte identidade reivindicatória, marcada pela luta por melhorias estruturais e sociais necessárias, e que se refletiu nas disputas políticas e na representatividade eleitoral das mais de sete mil famílias instaladas na região³.

Dessa forma, no presente trabalho, procuramos discutir o processo de ocupação do Conjunto Habitacional e as disputas políticas resultantes, em um recorte que se estende de 1978 a 1996, analisando as estratégias de aproximação utilizadas por políticos junto aos moradores do conjunto e as táticas de resistência e reivindicações que estes assumiam em relação aos primeiros, tendo como cenário os pleitos eleitorais do período, momento em que se pôde perceber o alinhamento ou a resistência política dos moradores com os grupos que motivaram a construção do residencial.

A temática aqui abordada insere-se no campo da História do Passado Recente ou História do Tempo Presente - como preferem denominá-la autores da envergadura de René Rémond (1996), François Bedárida (1996), Agnes Chauveau e Phillipe Tétart (2014).

\footnotetext{
${ }^{3}$ Somadas as duas etapas de construção, o Dirceu Arcoverde soma 7.294 unidades habitacionais entregues, com 3.040 unidades na primeira etapa e 4.254 unidades na segunda etapa.
} 
Esses últimos informam que esta produção segue no esteio do que foi proposto pelos historiadores dos Annales (sobretudo Marc Bloch e Lucien Febvre), que realçaram o papel do tempo presente no desenvolvimento da pesquisa histórica, mas apenas no âmbito do interesse e do entendimento. Todavia, somente a partir da segunda metade do século XX, a produção histórica passou a tratar temas ocorridos no tempo presente como relevantes para serem pesquisados, promovendo o que foi denominado de renovação da História do Tempo Presente, ao retomar seu vigor no campo historiográfico, estimulado pela vontade do homem contemporâneo de "reagir" e de explicar o seu presente (CHAUVEAU; TÉTART, 2014, p. 15). Mas, para além dos desafios, a História do Tempo Presente apresenta como principal especificidade o fato de pesquisar tempos e temas com os quais o pesquisador ou seus interlocutores de pesquisa conviveram, isto é, é a pesquisa em que há a relação física entre o historiador, seu tema e seu tempo.

Nessa renovação, os temas políticos foram os que primeiro se sobressaíram nesse campo de pesquisa, a partir do interesse de pesquisadores franceses, como René Rémond, em investigar sobre temas do campo dos direitos, e de François Bedárida, um dos fundadores do Instituto Histórico do Tempo Presente. Mas é importante esclarecer que o político não é tratado de maneira isolada, pois “em numerosas abordagens o político leva ao cultural, à opinião, etc." (CHAUVEAU; TÉTART, 2014, p. 14). É sob essa perspectiva renovada, e considerando essas orientações, que o presente texto aborda temas políticos na História do Tempo Presente.

Metodologicamente, a pesquisa procurou discutir a história e a memória desses moradores, destacando o seu protagonismo no cenário político-partidário da cidade em um ambiente que segregava de forma velada parte da população empobrecida de Teresina. Nesse diapasão, a pesquisa recorreu à revisão bibliográfica, à pesquisa hemerográfica e ao uso da metodologia da História Oral, mais especificamente a partir de entrevistas com trajetórias de vida e uso de entrevistas temáticas, conforme proposto por Lucília Delgado (2010), com os moradores mais antigos do bairro e que ainda residem na região. 


\section{O Itararé no cenário da política de moradia popular dos governos militares}

Ao procurar deter o olhar sobre os primeiros anos de ocupação do Itararé, deve ser destacada a intensa e tensa relação entre moradores e o Estado, à medida que este intervinha de forma mais ou menos presente nos caminhos tomados pelos moradores, indicando funções, delimitando serviços, normatizando regras de convívio social, segregando-os do restante da cidade. Entendemos que a construção do Conjunto se inseriu em um período-chave para a compreensão dos contornos que Teresina assumia, a partir da década de 1960, e sentia os efeitos do que foi considerado um surto populacional, resultado das fortes migrações no sentido campo-cidade, o que seria ampliado na década de 1970 (FONTINELES, 2015; MONTE, 2010).

Teresina, por ser a cidade com melhores índices de desenvolvimento social e econômico do estado, passou a atrair grandes contingentes de migrantes que, como meio de sobrevivência, submetiam-se à condição de subemprego e sobrecarregavam o frágil sistema de serviços públicos da cidade (LIMA, 2010).

Em busca de melhores condições de vida, a maioria desses migrantes chegava à capital sem condições mínimas para se estabelecer, sendo acolhidos por uma cidade sem estrutura para acomodá-los, mas impregnada pelo discurso de cidade moderna, deixando evidente o contraste entre o que se queria para a cidade e as precárias condições de que se dispunha para acolher a grande quantidade de migrantes que procuravam Teresina como refúgio (NASCIMENTO, 2007; MONTE 2010).

Assim, no início da década de 1970, Teresina encontrava-se mergulhada em problemas sociais decorrentes do agravamento da questão urbana e, dentre esse cenário, a construção civil despontava como um ramo promissor e capaz de propor soluções para o problema (LIMA, 2010 e 2003).

A construção do Conjunto Itararé insere-se como parte deste processo que objetivava abrigar os migrantes de baixa condição social e, assim, escamotear a questão ao deslocar parte da população pobre do estado do alcance do olhar. Ao mesmo tempo, essa população era retirada de áreas urbanas que vinham recebendo fortes 
investimentos imobiliários, a exemplo dos bairros Jóquei Clube, Fátima, São Cristóvão e Ilhotas (ARAÚJO, 2009).

Entretanto, as pessoas a quem o Estado desejava silenciar - tornando-as alvos de seus projetos modernizadores -, lançando mão das táticas do fraco, como define Michel de Certeau (1994), assumem o protagonismo da construção do Conjunto. Tornam-se produtoras de sua história e da cidade, por meio de suas vivências com o cenário urbano que Ihes era possibilitado, que caso em tela era o conjunto habitacional, entregue a elas como local de moradia e de convivência.

O Conjunto nasceu dentro de um processo de "modernização autoritária" e de especulação imobiliária, que afastava a população empobrecida da cidade dos centros administrativos e mesmo da população de maior poder aquisitivo. Conforme destacado por Medeiros, ele surgiu de

uma necessidade imediata de afastar os pobres, que moravam debaixo das pontes ou em terrenos invadidos nas "áreas nobres" da capital; num cenário de expansão da cidade e de forte especulação imobiliária, influenciando na valorização das terras localizadas entre o centro de Teresina e os conjuntos Dirceu I e II, que eram de proprietários ricos. (MEDEIROS, 2006, p. 18)

O conjunto teve como primeiro nome Conjunto Itararé, referido pela primeira vez pela grande mídia em uma reportagem do jornal O Dia, em 13 de abril de 1976, que relatava a visita do então governador, Dirceu Mendes Arcoverde, às obras de outro residencial popular da cidade de Teresina na época, o Parque Piauí. Em um trecho da reportagem, o governador informava sobre seu interesse em erguer um novo habitacional, com moradias mais simples e destinado às famílias que percebessem uma renda mensal de até um salário mínimo na região do Itararé4 (GOVERNADOR... O Dia, 13 abr. 1976, p. 03).

\footnotetext{
${ }^{4}$ O nome Itararé se refere a um antigo sítio que se localizava na região e fazia parte do bairro São Cristóvão. Esse local sediou, durante o governo de Alberto Silva, a instalação do Terminal de Petróleo de Teresina, atraindo o interesse do poder público em relação a sua dimensão territorial. Como o novo habitacional havia sido construído nas suas proximidades, deram-lhe o nome do antigo sítio (NASCIMENTO, 2005). Os primeiros moradores começaram a se instalar na região a partir de julho de 1977 (ITARARÉ. O Dia, 13 jul. 1977, p. 7), em condições infraestruturais bastante precárias.
} 
A implantação deste novo conjunto não significou apenas uma política habitacional do poder público na década de 1970, mas interferiu efetivamente na forma de sentir e de viver dos seus habitantes. Um exemplo disso é a conquista da moradia. Com o acesso a casa, esta transformada em lar, os primeiros moradores do Conjunto conseguiram o que muitos consideram como o maior bem material conquistado.

A casa constitui-se, então, como um bem a ser perseguido, fonte de sentimentos e significados que puderam ser capturados por meio das fontes consultadas, em especial por meio dos depoimentos de alguns dos primeiros moradores do Itararé, como Maria Neide da Silva, ao relembrar:

Nasci e me criei no município de Luís Correia, em um lugar chamado Carapeba... eu trabalhei de roça, nasci e me criei trabalhando de roça, era trabalhadora mesmo, rural, como se chama... Eu me casei com 16 anos e vim embora para Parnaíba, aí meu marido veio embora para trabalhar aqui, como sempre teve a dificuldade de serviço, aí ele se empregou aqui... Ficou eu lá com os meninos e ele aqui. Aí minha sogra disse: "Neide, filho cuidado longe de pai não dá certo"'... Eu vim embora em [19]76, no dia 3 de março de [19]76... Quando eu cheguei, comecei a trabalhar de vender merenda... Foi o tempo que houve as inscrições para o conjunto, aí eu fui me inscrever... [meu marido disse:] "Tu vai morar num lugar desse, imundo? Lá é muito feio, tu vai pra lá?” Mas eu vou morar no que é meu, não vou morar em meio de rua... (SILVA, 2013) ${ }^{5}$

Como uma das primeiras moradoras do Itararé, Maria Neide veio para o conjunto com seu marido e, à época, seus seis filhos. Dona de casa, sem instrução formal, migrante, seu exemplo representa perfil próximo a muitos outros moradores do Itararé.

Em seu depoimento, Maria Neide revela muito a respeito de como a cidade significava o novo conjunto, como um lugar não desejado, sentimento também compartilhado por ela. Esse sentimento da moradora, no entanto, não era maior que o desejo de possuir uma casa, independentemente dos sacrifícios enfrentados para obtê-la. Tais sacrifícios, conforme se notou com o transcorrer do tempo, foram muitos e duradouros, contrariando o discurso de preocupação social da política habitacional popular no período em estudo. É curioso, ainda, notar em seu relato que, ao afirmar que não moraria "em meio de rua" essa expressão não representava mera retórica, haja vista

\footnotetext{
5 SILVA, Maria Neide da. Entrevista concedida a Verônica Viana de Sousa e Douglas de Farias Sousa. Teresina, 2010. In: SOUSA NETO, Marcelo de; (et. al.), 2010.
} 
que desde a sua chegada em Teresina, ela e a família moravam de fato em ocupação irregular no bairro São Cristóvão, região leste da Capital.

Financiado pelo extinto Banco Nacional da Habitação - BNH, o conjunto foi erguido em duas etapas. A primeira realizada na administração do Governador Dirceu Mendes Arcoverde (1975-1979), quando inicialmente havia sido nomeado de Itararé. A segunda etapa, por sua vez, concluiu-se no governo de Lucídio Portella (1979-1983), recebendo o nome de Dirceu Arcoverde II. Ambas as etapas foram ancoradas no ideário da resolução do déficit habitacional na capital, em um período que revela muitas das contradições no discurso oficial de prosperidade e desenvolvimento urbano, propagado na época.

A primeira etapa foi inaugurada ainda na década de 1970, período em que os investimentos em obras públicas de grande porte eram entendidos como símbolo de progresso e modernidade nos cenários nacional e local, como sinônimo do desenvolvimento urbano prometido pelos governos autoritários que governavam o país. Investir, portanto, em conjuntos habitacionais era entendido como mecanismo de contenção das tensões sociais e visto como a intervenção do poder público no tecido da "urbis moderna” (FONTINELES, 2015).

Durante o período, a construção civil destacava-se entre as estratégias de investimento adotadas pelos Governos Militares para enfrentar a crise econômica e os conflitos sociais decorrentes do agravamento da questão urbana vivenciada pelo país (LIMA, 2010).

Como observa Lima,

Do ponto de vista do poder dominante, o problema mais importante não era a casa, mas a abertura de oportunidades de emprego não só para absolver as massas de trabalhadores semiespecializados, mas também para mobilizar um sem-número de escritórios de planejamento e dar trabalho às firmas e indústrias da construção civil, forças até então paralisadas na economia brasileira. [...] Montado nessas bases, o BNH garantiu sustentação social e política ao regime militar e ao seu modelo econômico. (LIMA, 2010, p. 66)

Assim, com a necessidade de estimular a economia e legitimar-se junto à população, os governos militares concentraram ações na política habitacional, facilitando o acesso à casa própria por meio de estímulo à construção civil, que, por sua vez, 
auxiliaria na recuperação da economia, ao gerar emprego para expressiva parcela da população, aliviando, desta forma, as diversas tensões sociais vivenciadas no período, figurando o BNH como um dos instrumentos para articular esses objetivos.

Como observa Maria Sílvia Barros Lorenzetti (2001), por seu caráter regulador do mercado de trabalho, a construção civil presta-se perfeitamente ao papel de aliviar as tensões sociais por sua capacidade de absorção de mão de obra. Nesse sentido, ainda em 1964, o Governo Federal "institui a correção monetária nos contratos imobiliários de interesse social, o sistema financeiro para aquisição da casa própria, cria o Banco Nacional da Habitação (BNH), e Sociedades de Crédito Imobiliário, as Letras Imobiliárias, o Serviço Federal de Habitação e Urbanismo e dá outras providências" (Lei n. 4.380/1964), definindo a política habitacional no país.

Com metas bastante ousadas, os efeitos da lei e a atuação do BNH começam de forma lenta, ganhando maior dinamismo com a incorporação de recursos do Fundo de Garantia do Tempo de Serviço - FGTS, em 1966, e a implantação do Sistema Brasileiro de Poupança e Empréstimo - SBPE, em 1967, que permitiram estruturar o Sistema Financeiro da Habitação - SFH. Desde a sua concepção, firma-se como princípio básico do SFH a autossustentação financeira, realizada por meio da correção monetária sobre as prestações e a dívida, com o fim do retorno dos recursos captados e a lucratividade da operação. Entretanto, o modelo aplicado para considerar a habitação como uma mercadoria a ser comercializada gerou distorções sociais graves, resultado da incompatibilidade entre o reajuste periódico das prestações e dos saldos devedores, e da baixa capacidade de pagamento das famílias de menor renda, agravada ainda pela posterior recessão econômica (LORENZETTI, 2001).

Portanto, em seus primeiros anos, o que se observa é que o BNH concentrou suas ações nas camadas mais carentes da população, priorizando programas de remoção de favelados para apartamentos ou casas-embrião de conjuntos habitacionais.

Já no início da década de 1970, reconhecendo como clara a dificuldade do SFH em atender à população de menor renda, o governo federal instituiu o Plano Nacional de Habitação Popular - PLANHAP e do correspondente Sistema Financeiro da Habitação Popular - SIFHAP, que atuavam nos estados por meio das Companhias de Habitação - 
COHABs, que, por sua vez, pouco alteraram o déficit habitacional do país por seu caráter segregador, considerando que os recursos alocados tornavam-se de difícil acesso à população de baixa renda, que não conseguia arcar com os custos financeiros dos contratos.

As dificuldades encontradas pelo BNH em cumprir seus objetivos já eram foco da atenção do então senador piauiense, Alberto Tavares Silva, em 1980. Por ocasião de conferência na Associação Comercial Piauiense, acerca da questão habitacional e energética no estado e em relação aos projetos habitacionais implantados pelo Banco, Silva observa que

À medida que alguns projetos foram sendo implantados, logo ficaram patentes dois fatores da maior importância, e que por muito tempo impediram o pleno desenvolvimento da inciativa governamental, a saber, a incapacidade financeira dos Estados para arcar com o pesado ônus da infraestrutura de serviços com água, esgoto, energia, urbanização etc., e o baixo poder aquisitivo dos mutuários, na maioria dos casos ficando inadimplentes em pouco tempo, criando sério problema social para o programa das COHABs. [...] O que se tem visto é o espetáculo triste de uma família com seis a dez dependentes ocuparem uma casa com um quarto. (SILVA, 1980, p. 45-6)

Notadamente, Alberto Silva referia-se às dificuldades enfrentadas pelo Conjunto Dirceu Arcoverde, por ele ainda nomeado de Itararé ${ }^{6}$, que, pelo mero acaso, aproxima-se do exemplo citado pela senhora Maria Neide da Silva, que chegou ao conjunto com seis crianças e, em poucos anos, sua prole chegaria ao total de dez. Dessa forma, as críticas de Silva exemplificam as contradições resultantes do modelo de moradia popular adotado no país, muitas vezes excluindo a população que deveria priorizar. Como destaca Lorenzetti,

\footnotetext{
${ }^{6}$ Apesar de, à época, o conjunto já ter tido seu nome modificado para Dirceu Arcoverde, Alberto Tavares Silva continuou a nomeá-lo de Itararé, o que pode sugerir que o mesmo se deve ao fato de, por muitos anos, após a mudança no nome do conjunto, significativa parcela da população da cidade ainda continuar a chamá-lo pelo antigo nome. Também não pode ser descartado que Dirceu Arcoverde era opositor político-partidário de Alberto Silva. Não reconhecer o nome oficial do conjunto, que fortalecia o significado ou importância de Dirceu Arcoverde, pode representar uma tentativa de silenciar, mesmo que de forma involuntária, a imagem deste na memória dos moradores do conjunto e do estado. Por ironia, Alberto Silva ocupava a vaga no senado deixada por Dirceu quando de sua morte em 1979, 44 dias após ter assumido o mandato de senador. Acerca dessas divergências na política piauiense ver: FONTINELES, Claudia Cristina da Silva. O recinto do elogio e da crítica: maneiras de durar de Alberto Silva na memória e na história do Piauí. Teresina: EDUFPI, 2015.
} 
embora o déficit concentre-se nas camadas de mais baixa renda da população, boa parcela dos recursos do setor permanece alocada em financiamentos para as classes de maior poder aquisitivo. Mesmo nos programas especificamente direcionados para famílias com renda de até três ou cinco salários mínimos, como é caso dos financiamentos feitos pelas COHABs, o atendimento é "elitizado", com a concentração das aplicações efetivas no limite máximo. [...] O caráter elitista e concentrador de renda pode ser medido em números: até 1975, o total de investimentos do $\mathrm{BNH}$ relativos às faixas de renda situadas entre 1 e 5 salários mínimos não passou de 9\%. (LORENZETTI, 2001, p. 18)

Em Teresina, apesar de seus limites, a política habitacional implantada por meio da COHAB-PI, resultou em importantes alterações no tecido urbano da cidade, que intensificava suas contradições sociais à medida que a cidade se espalhava em diversas direções, exemplificada, como interesse do presente trabalho, por meio da construção do conjunto Itararé.

Na construção do conjunto, a ação governamental na cartografia social e urbana da cidade não se caracterizou pela supressão das demandas sociais vivenciadas pela população atendida, nem tampouco supriu as deficiências infraestruturais pósinauguração, condição esta que colabora para entender muitas das carências sentidas por habitantes residentes em Teresina na época, elementos que permitem ao pesquisador, como destaca Pesavento (2007), discutir as novas formas de sociabilidade que vão compor o quadro urbano que se deseja analisar.

Após sua conclusão, o conjunto foi entregue aos seus moradores sem inauguração oficial e em meio às mais precárias condições de saneamento e outros serviços públicos. A ausência de energia elétrica e de serviço de água encanada7, a falta de calçamento, a inexistência de um sistema de saúde adequado e um ineficiente sistema de transporte coletivo fizeram nascer no seio desse conjunto uma forte identidade reivindicatória, de luta por melhorias infraestruturais necessárias a uma melhor qualidade de vida de seus moradores. Dessa forma, à medida que os moradores começavam a ocupar as casas e a iniciar as transformações dos espaços do conjunto, estes também começavam a se articular e a ganhar representatividade no cenário político partidário da cidade, o que será tratado a seguir.

\footnotetext{
7 Apesar das casas terem sido entregues com canalização para água, o sistema de abastecimento de água para o bairro não havia sido construído. $O$ abastecimento de água era realizado por meio da coleta em apenas dois chafarizes.
} 


\section{Itararé: de indesejado problema a desejado colégio eleitoral}

Com a ocupação das casas do Itararé pelas 3.040 famílias previstas pelo projeto inicial e começadas as obras de ampliação do conjunto, que receberia mais 4.254 casas, seus moradores começaram a despertar atenção para sua representatividade no coeficiente eleitoral da cidade. Sua importância pode ser verificada, por exemplo, a partir da mudança do nome do Conjunto e do desejo de perpetuar, na memória da população, a imagem de um de seus governantes, Dirceu Mendes Arcoverde, estabelecendo para seus moradores, por meio do nome do conjunto, um importante "lugar de memória"8 (NORA, 1993).

Em 3 de abril de 1979, os jornais O Estado e O Dia publicaram matérias destacando o desejo da comunidade do Itararé, representada pela Associação Unida do Itararé, de mudar o nome do conjunto para Dirceu Arcoverde, em homenagem ao ex-governador, recém-falecido após assumir cadeira no senado (MORADORES... O Estado. 03 abr. 1979, p. 01; e SETE MIL... O Dia, 03 abr. 1979, p. 04).

Para o vereador Jerônimo Rodrigues Alves ${ }^{9}$, ex-assessor de Dirceu Arcoverde e autor do requerimento que pedia a mudança do nome do conjunto, a alegação era que

[...] Dirceu Arcoverde quando governador do Estado demonstrou preocupação com as famílias de menor poder aquisitivo ao construir mais de três mil casas no conjunto Itararé destinadas a pessoas que ganham entre um e três salários mínimos. Tomou por base, também o fato do próprio povo pedir a denominação de Dirceu Arcoverde para o conjunto Itararé, como mostra um documento contendo quase oito mil assinaturas de moradores do conjunto, dando força ainda mais ao Projeto de lei apresentado à Câmara Municipal. (NOME... O Dia, 03 abr. 1979, p. 04)

\footnotetext{
8 Para Pierre Nora (1993), os lugares de memória são lugares em todo o sentido do termo, abrangendo desde objetos a abstrações e em seus diversos graus, modificando ou interferindo na forma com que os indivíduos os significam. Ainda segundo o autor, "só é lugar de memória se a imaginação o investe de aura simbólica" (1993, p. 21) e de que estes devem possuir uma "vontade de memória", deve ter na sua origem uma intenção memorialista que garante sua identidade. No caso do Itararé, restou clara a iniciativa de lideranças do conjunto, ligadas ao ex-governador e senador falecido, em perpetuar a imagem do líder político por meio da alteração do nome do conjunto, estratégia que resultou efeitos em toda a cidade que hoje, independente da nomenclatura dos bairros próximos, reconhecem a região pelo nome de "Grande Dirceu", reverberando na memória dos moradores da cidade a imagem do político.

9 Jerônimo Rodrigues Alves era coronel da Polícia Militar do Piauí e foi vereador por Teresina e suplente de deputado estadual filiado à ARENA. Ocupou ainda a subchefia da Casa Militar nos Governos de Petrônio Portela e Helvídio Nunes.
} 
Após votação tranquila, que contou com o apoio de todos vereadores arenistas e emedebistas, foi aprovado o requerimento apresentado, mudando o nome do conjunto para Dirceu Arcoverde que, posteriormente, seguiu para ser sancionado pelo prefeito Raimundo Bona Medeiros (NOME... O Dia, 03 abr. 1979, p. 04).

É importante salientar que a iniciativa de mudança para o nome do conjunto partiu da Associação Unida do Itararé, entidade fundada a 24 de janeiro de 1978, tendo à frente o senhor Francisco de Assis Alves, mais conhecido como "Chico Alves", suplente de vereador pela ARENA e funcionário da Secretaria de Trabalho e Ação Social, que foi enviado para o Itararé com o objetivo de desenvolver uma política de atendimento e apoio aos habitantes do conjunto.

Vinculado partidariamente aos governos de Dirceu Arcoverde e Lucídio Portella, condição que lhe permitiu acesso à posição privilegiada no cenário político da cidade e personagem importante em disputas eleitorais futuras, Francisco Alves foi responsável por articular e apresentar ao presidente da Câmara Municipal de Teresina, vereador Moisés Elias Caddah, um abaixo-assinado com mais de sete mil assinaturas reivindicando a mudança do nome do conjunto.

Ao ser relembrada a relação entre memória e lugares, em que as memórias individual e coletiva têm nos lugares uma referência importante para a sua construção (NORA, 1993), a mudança do nome do conjunto serviria ao propósito de manter viva na memória dos seus moradores a imagem do governante que lhes permitiu o acesso à moradia tão sonhada e, juntamente com esta memória, a imagem do grupo político a que Dirceu era vinculado.

Pode-se, ainda, ao discutir a mudança do nome do Conjunto, substituído pelo nome de uma proeminente figura política do Estado, fazer inferências às reflexões de Michael Pollack acerca da memória coletiva e sua capacidade de produzir um sentimento de pertencimento às fronteiras socioculturais, quando este destaca que a memória coletiva de um determinado grupo "ao definir o que é comum a um grupo e o que, o diferencia dos outros, fundamenta e reforça os sentimentos de pertencimento e as fronteiras socioculturais" (PLLACK, 1989, p. 03). Dessa forma, pode-se depreender que a 
mudança do nome gerou, e continua a gerar, reverberações na memória dos moradores do conjunto e da cidade, por meio de uma reelaboração da memória social resultante desta mudança.

Por outro lado, houve também um movimento de resistência haja vista que muitos moradores recusaram adotar o novo nome, o que implicou na adoção simultânea dos dois nomes, repercutindo até o presente, em que é possível encontrar moradores que ainda denominam a região como Itararé.

Os lugares - e como estes são significados - são importantes referências na memória dos indivíduos e, por consequência, as mudanças empreendidas nesses lugares, inclusive em sua denominação, repercutem na vida e na memória dos grupos. Como alerta Halbwachs (1990), a memória aparentemente mais particular remete a um grupo, em que cada indivíduo carrega em si lembranças saturadas pelo coletivo, de maneira que, ainda que não se esteja em presença destes, os sentidos se constituem a partir do emaranhado de experiências coletivas que se percebe como unidade que parece ser somente do indivíduo. Ainda segundo esse autor, dificilmente se pode lembrar fora deste quadro de referências coletivas, no qual o outro ocupa papel de destaque nos processos de produção da memória e da rememoração, que se modifica e se rearticula conforme a posição que se ocupa e as relações que se estabelece.

Nesse sentido, a mudança do nome do conjunto trazia em seu esteio o desejo de fortalecer os vínculos daquela população com a memória construída acerca do governante recém-falecido e, por conseguinte, com o modelo político partidário que representava. Essa memória seria renovada a cada dia pelos moradores do conjunto que, com as 7.294 famílias beneficiadas em suas duas etapas, sinalizavam para um potencial político que não podia ser desprezado, e que se confirmou com a eleição, em 1982, de Maria Irmani Campos Veloso Alves, assistente social, líder comunitária e esposa de Francisco Alves, como vereadora por Teresina, pelo Partido Democrático Social (PDS).

Irmani Veloso, como conhecida por seus eleitores, pôde contar com o forte apoio dos moradores do conjunto para compor os seus 2.626 votos obtidos. Sua eleição, bem como a mudança do nome do conjunto está diretamente relacionada às marcas do 
Tavares Silva ${ }^{10}$. Este, por seu turno, enfatizava a importância das obras públicas e de valores como a técnica, a ciência e o progresso como elementos que permitiriam o Piauí inserir-se no "Brasil Grande Potência", ideia difundida em todo o país no período em tela (FONTINELES, 2015).

Nessa perspectiva, em seu discurso de governo, Dirceu Arcoverde difundia como sendo prioridade de sua gestão o setor social, ao comprometer-se em reduzir a miséria e o desemprego em todo o estado, por meio do fortalecimento dos setores de assistência social, ao apoiar as ações da Secretaria de Trabalho e Ação Social e da política habitacional, que ficava a cargo da COHAB-PI (SANTOS, 1982).

A importância da assistência social como marca de seu governo foi de fato reafirmada pela criação da própria Secretaria de Trabalho e Ação Social que, segundo o vice-líder do governo na Assembleia Legislativa do Estado, deputado Carlos Augusto, possuía por metas "promover o bem estar social do homem piauiense" (CRIAÇÃO... 0 Dia, 23 e 24 mar. 1975, p. 05), argumento reafirmado anos depois pelo prefeito da Capital, Raimundo Wall Ferraz. Por ocasião da entrega de um posto médico e de uma ambulância no Conjunto, o prefeito destacou em sua fala o compromisso social do governo de Dirceu Arcoverde, ao afirmar que este, “distancia[va]-se das obras de fachada para cuidar dos problemas sociais" (GOVERNADOR... O Dia, 28 out. 1977, p. 08).

A centralidade semântica da defesa social do homem ganhou destaque nas falas do governador Dirceu Arcoverde desde seu discurso de posse (PIAUÍ, 1975) e se mantivera até ao final de seu mandato, figurando o conjunto habitacional Itararé como um dos ícones de tal proposta governamental e de propaganda.

\footnotetext{
${ }^{10}$ No primeiro governo de Alberto Silva, Dirceu Arcoverde foi Secretário de Saúde, sendo apontado pelas lideranças da ARENA, capitaneadas por Petrônio Portella, como alternativa viável às eleições indiretas de 1974 para suceder a Alberto Silva, como estratégia do grupo para recuperar o comando político do estado. Essa indicação não esteve diretamente ligada às decisões de Alberto Silva, o que gerou uma disputa entre este e seu sucessor, Dirceu Arcoverde. As pesquisas de Fontineles (2009) tratam dos desdobramentos de tais disputas na história do Piauí.
} 
Essas mesmas marcas também deram sustentação ao seu discurso como candidato ao senado, o que permitiu uma maior penetração de suas propostas junto aos segmentos da população de menor renda do estado, onde a construção do Itararé ganhou destaque em sua campanha eleitoral. Tal obra, ressignificada como favor pessoal do então governador, culminou no apoio massivo dos moradores do Itararé, que, apesar de não serem determinantes para sua eleição, contribuíram significativamente, e deram esmagadora maioria dos votos ao candidato Dirceu Arcoverde no colégio eleitoral a que pertencia o Conjunto.

Tabela 01: Eleições 1978 - Resultado para Senador ${ }^{11}$

\begin{tabular}{|lllll|}
\hline Cargo & Candidato & Partido* & Votação & Situação \\
\hline Senador & & & \\
\hline & Alberto Tavares Silva & Não Informado & 260.007 & Não Eleito \\
& & & \\
\hline Dirceu Mendes Arcoverde & Não Informado & 290.218 & Eleito \\
\hline Votos Brancos & - & 31.837 & - \\
\hline & - & & 16.191 & - \\
\hline
\end{tabular}

Fonte: Tribunal Regional Eleitoral do Piauí - $\quad$ TRE. Disponível em: <http://www.justicaeleitoral.jus.br/arquivos/tre-pi-resultado-eleicao-para-senador-suplente-senadordeputado-federal-deputado-estadual-1978>. Acessado em: 04 abr. 2016.

Para que se exemplifique a importância política do Itararé para a eleição de Dirceu Arcoverde ao Senado, em 1978, basta que seja lembrado que em Teresina, em todos os outros colégios eleitorais da capital, o concorrente de Dirceu, o ex-governador Alberto Tavares Silva, teve maior número de votos, perdendo apenas nas urnas do Itararé, o que o motivou a solicitar e obter a realização de uma recontagem de votos das urnas do Conjunto (SILVA, 2008, p.27), mas sem alterar seu resultado final.

\footnotetext{
${ }^{11}$ Apesar de não informado pelo TRE-PI, os dois candidatos pertenciam a ARENA.
} 
Entretanto, as eleições de 1978 apenas deram início a uma série de embates políticos eleitorais no Conjunto, onde as eleições de seus primeiros vereadores, anos depois eleitos com forte participação de votos de moradores do Itararé, representaram momentos importantes de sua história. Partidos políticos e movimentos populares passaram, assim, a atuar de forma mais efetiva no Conjunto, inclusive de forma violenta, na defesa de interesses ou reagindo a situações consideradas por seus protagonistas como insuportáveis.

Entre os personagens de destaque no cenário político partidário no Itararé, sobressaíram-se, como já anteriormente citado, Chico Alves e Irmani Veloso, agentes representantes do Governo do Estado no Conjunto e que tiveram relevância também enquanto lideranças políticas.

Tendo sua imagem entranhada no Conjunto por seu trabalho como assistente social, Irmani Veloso lançou-se candidata à vereadora nas eleições 1982 pelo PDS (Partido Democrático Social), contando com o apoio de seu esposo e suplente de vereador, Chico Alves, saindo vitoriosa com um total de 2.626 votos, conseguidos, em sua maioria, nas urnas do Itararé.

Para que se possa ter uma ideia da relevância do Itararé para o cenário político partidário da cidade, Chico Alves, candidato a vereador pela ARENA nas eleições de 1976, antes da existência do Conjunto, obteve um total de 1.161 votos, rendendo-Ihe apenas a condição de suplente, o que deixou clara a necessidade de novas estratégias para ampliar o número de votos necessários para eleger-se vereador, surgindo o Itararé como resposta.

Como observa Medeiros (2006), os esforços pela busca de votos concentraram-se na figura de Irmani Veloso, que reconhece que a decisão de se candidatar não nasceu de seu desejo, mas de circunstâncias que podem ser observadas em seu depoimento.

A desistência do meu ex-marido em não mais sair candidato, a pressão dos próprios moradores e do meu esposo, que não achava justo entregar todo nosso trabalho a outra pessoa, já que não teriam para comunidade compromisso igual ao nosso. (VELOSO, apud., MEDEIROS, 2006, p. 27) 
$\mathrm{Na}$ fala de Irmani, fica ressaltada a conveniência familiar de quem poderia atrair maior número de votos em um embate eleitoral, mas é possível observar, também, um sentimento de posse sobre o Conjunto, configurado no desejo de não entregar, em suas palavras, "todo o nosso trabalho a outra pessoa".

Mas quem de fato seria essa outra pessoa a quem a ex-vereadora se referia? Em estudo sobre as manifestações políticas no conjunto Dirceu Arcoverde, Manoel Sousa Medeiros (2006) destaca que, paralelamente ao fortalecimento do PDS e do grupo político representado no Conjunto por Irmani Veloso, começavam a emergir vozes discordantes ao modelo político estabelecido, a partir de movimentos eclesiásticos na região ligados à Igreja Católica, em especial, um grupo nomeado de Juventude Franciscana (ou JUFRAN como ficou conhecido), que passou a se opor sistematicamente ao Governo do Estado no Itararé.

As disputas entre o grupo político representado por Irmani Veloso e os membros do JUFRAN, assumem especial destaque no presente escrito, uma vez que seus desdobramentos ajudaram a compor o cenário político partidário da cidade alguns poucos anos depois.

O JUFRAN nasceu entre as ações promovidas pela paróquia de São Francisco de Assis, como um movimento eclesiástico de jovens que se propunha a dar conforto espiritual e assistência social aos seus moradores, mas que começou a ganhar também contornos políticos em suas ações, tornando-se a principal oposição aos representantes do Governo do Estado no Itararé, sobretudo, por suas reinvindicações de melhorias infraestruturais e sociais para o Conjunto.

O grupo foi responsável pela formação ou, ao menos, pelo despertar de lideranças importantes para história do Conjunto e da cidade, pois enquanto promovia a reflexão religiosa de acolhimento do outro e da igualdade entre as pessoas, fomentava também o engajamento político na busca pela a garantia de direitos.

Essa trajetória do JUFRAN é relembrada por um de seus antigos membros, Humberto Coelho Silva, ao destacar que 
tinha todo um movimento organizado pela Igreja Católica. Por aqui tinha frades, o Frei Domingos, e as irmãs que já moravam aqui no bairro quando eu cheguei, o Frei Domingos era quem dava assistência uma vez por semana, e aí eu me engajei, aí tinha também o grupo JUFRAN, que era um grupo ligado à igreja, mas um grupo muito engajado na vida social e política do bairro. O JUFRAN que não era um grupo com características de muitos desses grupos de jovens que a gente conhece hoje, da igreja católica, que a ação é muito voltada para questão interna da igreja, o JUFRAN, participava da vida social e política do bairro, era assim um espaço da reunião da juventude, e gerava, assim, a organização, a participação das pessoas, dos jovens, a gente refletia além dessa questão do engajamento da igreja, mas tinha também a parte da formação, de uma preocupação muito grande que o grupo tinha que era a formação intelectual da gente. (SILVA, apud. MEDEIROS, 2006, p. 29)

Por intermédio do JUFRAN, a juventude do bairro procurava fazer-se notar na comunidade, expor suas ideias e construir a crítica ao Governo do Estado e aos Governos Militares, sentidos àquele instante como os responsáveis por muitas das mazelas enfrentadas por eles e seus familiares. Para esses jovens, os representantes do Estado no Conjunto, à época, Irmani Veloso e Chico Alves, personificavam esses governos.

Os atritos foram inevitáveis, cada segmento defendia seu ponto de vista como lógico e justo. Acerca da resistência ao seu trabalho no Conjunto, Irmani Veloso, em entrevista concedida a Manoel Sousa Medeiros, relembra que

O poder sempre incomoda, causa invejas e inimigos, principalmente para os incompetentes que, em vez de trabalhar, atacam os que trabalham. $O$ crescente desenvolvimento do Dirceu, os resultados eleitorais atraem muitos adversários, muitos corrupiões, aqueles que não fazem nem seus ninhos, usam os dos outros locais, tivemos o PC do B, do Osmar Júnior, atual vice-governador, tão diferente ideologicamente, que era representado pelo ex-vereador Anselmo Dias. (...). Eles faziam movimentos sociais para protestarem as nossas ações. Digo sinceramente, nunca me irritaram, considerava um direito que tinham. Contudo, o meu ex-marido reagia e muitas vezes com violência. (VELOSO, apud. MEDEIROS, 2006, p .30)

No depoimento da ex-vereadora, resta claro o incômodo causado por seus opositores que deixaram marcas importantes em sua memória e como essa memória é ressignificada, ao deixar transparecer que suas ações e intensões para a melhoria do Conjunto não eram compartilhadas por toda a comunidade e de que havia mobilização efetiva ao enfrentamento no campo das ideias e mesmo para o enfrentamento físico, ao reconhecer que seu marido "reagia e muitas vezes com violência” aos opositores. 
O evento relembrado pela ex-vereadora refere-se a um episódio, em 1982, envolvendo seu ex-marido, Chico Alves, e José Anselmo Oliveira Dias, líder comunitário e, posteriormente, eleito vereador de Teresina pelo PC do B.

Por ocasião de uma reunião que acontecia em uma invasão de terras nas imediações do Itararé, que ganhou o nome de Boa Esperança, reuniram-se no mesmo espaço alguns membros do JUFRAN, Irmani Veloso e Chico Alves. Em razão de um enfrentamento de ideias, deu-se início a uma discussão acalorada, em que ânimos se exaltaram, o que culminou em ameaças e na intervenção conciliatória da própria população.

No dia seguinte à reunião, Anselmo Dias, um dos membros do JUFRAN, que teria sido ameaçado durante a reunião na invasão Boa Esperança, relata que foi fisicamente agredido.

(...) Aí eu estava saindo para universidade que ficava a parada de ônibus bem na porta da casa dele, ali quase e ele aproveitou a oportunidade, ele pessoalmente me bateu, me fez lesão corporal, só não me matou porque não quis mesmo, (...) Mas ele me bateu bastante, me chutou, me bateu de revólver na cabeça, no ouvido, na boca né (...) Depois fizemos pichação em vários muros do conjunto, aqui mesmo nesse muro da UESPI, era todo pichado com essa palavra de ordem: pistoleiro não dá pé pra morar no Itararé, fora Chico Bala. (DIAS, apud. MEDEIROS, 2006, p. 30-1)

O que se pode observar pelo depoimento de Dias é a instabilidade política vivida no Conjunto, provocada pela consciência de sua representatividade no cenário político partidário no Itararé e pelas disputas entre aqueles que desejavam ser os legítimos representantes de seus moradores.

Acerca do episódio, fortemente marcado nas memórias de Dias, este ganhou tons mais amenos em relato de Chico Alves sobre o mesmo. Mais de duas décadas depois do ocorrido, já divorciado de Irmani Veloso, e fortemente engajado em uma Igreja evangélica, Chico Alves ressalta que seus opositores no JUFRAN eram muito agressivos, mas que isso era apenas a rebeldia da juventude, e relembra,

era só folia da juventude, porque na verdade quem era visto do lado dos militares era, né. Você sabe que naquele tempo as pessoas se revoltavam 
mesmo, esse que é vice-governador era muito amigo do Anselmo que vivia aqui dentro. (...) Na época foi uma coisa assim né, porque eles eram muito agressivos, de todo jeito é de baderna mesmo, o Anselmo era muito novo, mas hoje, eu tenho uma amizade muito grande com o Anselmo, muito grande, admiro o Anselmo como pessoa. Inclusive quando ele ganhou como vereador eu fui um dos primeiros a ir lá parabenizar ele, e me tornei amigo dele. Certo, se houve algum atrito, foi coisa mesmo da política e ele era jovem, eu era jovem (...), foi uma coisa lamentável, uma coisa, como te falei há pouco, coisa que acontece, coisa que acontece, você não sabe nem por que (...) eu acho que tudo aquilo que você faz que é irracional, a gente se arrepende. (DIAS, apud. MEDEIROS, 2006, p. 32).

Irmani Veloso ainda se reelegeu vereadora nas eleições de 1988, com 1.630 votos pelo Partido da Frente Liberal (PFL) e ao relembrar seu trabalho na comunidade do Itararé, depois Dirceu Arcoverde, a ex-vereadora destaca seu compromisso com a comunidade e com a população mais carente ao ressaltar,

primeiramente, política para mim nunca foi fim, mas, sim, meio de servir, principalmente, aos mais carentes. Tudo fizemos para melhorar a vida dos que aqui residiam e prova é que o Dirceu apresenta um desenvolvimento superior a bairros muito mais antigos. Não lutava por causa do povo, mas por causas nossas, já que também era uma moradora. Agia em todas as frentes: assistencial, política e de desenvolvimento. (VELOSO, apud. MEDEIROS, 2006, p. 35)

No fragmento do relato, a ex-vereadora se posiciona como uma igual os demais moradores, porque também era moradora, e que lutava pelos moradores do Conjunto e por si. Entretanto, em seu depoimento a mesma minimiza as condições em que chegou ao Itararé, como representante do Governo do Estado, o que por si já a tornava uma diferente. Minimiza, ainda, o fato de que nem toda a comunidade compreendia da forma retratada o trabalho realizado por ela no Conjunto, como é possível verificar em relato de uma antiga moradora ao descrever uma relação muito próxima entre assistência e controle sobre os moradores do Itararé,

(...) Eu achei que foi boa naquela época, não sei se no caso de hoje fosse igual, pois antes o povo era carente de informações. Eles deixavam entender que ela era a dona de tudo e em cada repartição pública era um verdadeiro curral eleitoral. No caso, ela achava que ali ela, aquele povo ali era dela, quer dizer, é o cara trabalhava numa escola aí aquela escola era manipulada com essa questão da política né... (OLIVEIRA, apud. MEDEIROS, 2006, p. 35) 
Talvez o não reconhecimento, ou descontentamento, com o trabalho realizado junto aos moradores do então Dirceu Arcoverde tenha ficado patente nas eleições de 1992, quando candidata à reeleição, Irmani Veloso, pela mesma legenda partidária, não conseguiu mais eleger-se e desde então não se candidatou a cargo eletivo.

Quatro anos depois, nas eleições de 1996, um dos antigos líderes do JUFRAN, Anselmo Dias, elegeu-se vereador por Teresina pelo PC do B, com um total de 2.627 votos, em sua maioria, obtidos em urnas do Dirceu Arcoverde. Sua eleição representou parte dos desdobramentos que tiveram sua origem quase uma década antes e que continuaram a reverberar nas décadas que se seguiram.

Observa-se, entretanto, que a rejeição ao modelo político representado por Irmani Veloso e a vitória de um representante de movimentos populares do Conjunto, Anselmo Dias, insere-se em um contexto mais amplo de mudanças. Em nível nacional, com o fim dos Governos Militares e, sobretudo, em nível local, com o retorno ao Governo do Estado de Alberto Tavares Silva, em 1987, opositor ao grupo político ao qual Irmani Veloso se filiava, fazendo com que esta perdesse importantes apoios ao desenvolvimento de seu trabalho, refletindo em sua não reeleição em 1992.

Como representantes do Governo do Estado, Irmani Veloso e Chico Alves assumiram um protagonismo importante na fixação e assistência de moradores e nos contornos assumidos pelo Conjunto no início de sua história, em uma época que os governos estadual e municipal tinham o interesse na retirada da população pobre de algumas áreas da cidade e em enviá-los para o Itararé, projeto que se mostrou vitorioso, ao se observar o processo de crescimento do mesmo.

Em seu propósito, o Governo do Estado e seus representantes no Conjunto passaram a receber a sistemática crítica de parte de seus moradores e movimentos populares organizados, a exemplo do papel assumido pelo JUFRAN, oposição que logo ganhou conotação político-partidária, passando a disputar em pleitos eleitorais vitoriosos a representatividade dos moradores e a traçar um novo modelo de organização material e social da região, denunciando o esgotamento do modelo limitado de acolhimento dos anos iniciais do Itararé. E, assim, da disputa entre os representantes de cada segmento, 
muitos de seus desdobramentos ajudaram e ajudam a compor a história do Conjunto e da cidade, e que tiveram seus primeiros capítulos escritos nas disputas eleitorais de 1978.

\section{Considerações finais}

Com a saída prematura de Dirceu Arcoverde do cenário político do Estado, em decorrência de seu falecimento, após ter assumido cadeira no Senado Federal, novas disputas pelo controle político do Estado e da cidade iniciaram-se e, em meio a estas, os moradores do Itararé inseriram-se com a pauta da busca de melhores condições de sobrevivência, desejando, também, fazer parte dos sonhos da cidade que os empurrou para suas margens, fazendo surgir uma nova face de Teresina que, por meio da pesquisa, é dada a conhecer.

A cidade tem sua "história múltipla", histórias que se entrecruzam, permitem que se aproximem de suas diversas faces e a cada uma destas se façam questões que a ressignificam, viabilizando o surgimento de uma cidade até então desconhecida. De alguma forma, é a esta missão que se propõe o presente texto ao apresentar algumas das faces da cidade, fazendo surgir a possibilidade de uma cidade nova, ressignificada por seus usuários.

O Itararé, como sonho e pesadelo, constituiu-se como uma das faces da cidade de Teresina. Criado com o propósito de "desfavelamento" da zona leste da capital piauiense, e em meio às políticas habitacionais promovidas pelos governos militares a fim de conter as tensões sociais, o Conjunto foi entregue aos seus moradores, apresentando problemas infraestruturais sérios, o que fez com que parte de seus habitantes desistissem de suas casas.

Muitos outros, entretanto, permaneceram e passaram a interferir de forma efetiva na transformação dos espaços do conjunto, escrevendo novos capítulos da história do residencial e da cidade.

As eleições para o senado, disputadas por Dirceu Arcoverde e Alberto Silva, marcam apenas um dos capítulos da história do Conjunto e o início de outras disputas. 
Novas histórias se seguiram ao longo da década de 1980, onde os moradores do Itararé foram personagens de destaque e protagonistas das mais diversas disputas, incluindo a busca por moradia digna, em lutas que se repetem e alongam-se aos dias de hoje e que fizeram do "Grande Dirceu", herdeiro legítimo do indesejado Itararé, uma das belas faces assumidas por Teresina e que ajudam a recontar a história da cidade e de sua gente.

\section{Referências}

ARAÚJO, Cristina Cunha de. Trilhas e estradas: a formação dos bairros Fátima e Jockey Clube (1960-1980). 2009, Dissertação (Mestrado em História) - UFPI - PPGHB, Teresina, 2009.

BÉDARIDA, François. Tempo Presente e Presença na História. In: FERREIRA, Marieta de Moraes; AMADO, Janaína. (Coords.) Usos \& abusos da história oral. Rio de Janeiro: FGV, 1996.

BRASIL. BNH. Contrato de empréstimo entre o BNH e a COHAB-PI, com a interveniência do Estado do Piauí [Projeto: Itararé. Objeto: 3040 casas]. Rio de Janeiro, 30 jun. 1976.

CERTEAU, Michael. A invenção do cotidiano1: artes de fazer. Petrópolis: Vozes, 1994.

CHAUVEAU, Agnes; TÈRTARD, Philippe (Orgs.). Questões para história do tempo presente. São Paulo: EDUSC, 2002.

CRIAÇÃO de Secretarias. O Dia, 23 e 24 mar. 1975, p.05.

DELGADO, Lucília de Almeida Neves. História oral: memória, tempo, identidade. 2 ed. Belo Horizonte: Autêntica, 2010.

DIAS, José Anselmo Oliveira. Entrevista concedida a Manoel Sousa Medeiros, em 29 de outubro de 2005. In: MEDEIROS, Manoel Sousa. A redemocratização e às manifestações políticas no bairro Dirceu Arcoverde (1984 a 1985). 2006. Monografia (Curso de História) Universidade Estadual do Piauí - Campus Clóvis Moura, Teresina, 2006.

DIRCEU visita os conjuntos e diz está satifeito. O Dia, 13 abr. 1976, p. 03. 
FONTINELES, Claudia Cristina da Silva. O recinto do elogio e da crítica: maneiras de durar de Alberto Silva na memória e história do Piauí. 1. ed. Teresina: Edufpi, 2015.

GOVERNADOR homenageado no Itararé. O Dia, Teresina, 28 out. 1977, p. 01.

HALBWACHS, Maurice. A memória coletiva. São Paulo: Vértice, 1990.

ITARARÉ. O Dia, 13 jul. 1977, p.7.

LIMA, Antônia Jesuíta de. As multifaces da pobreza: formas de vida e representações simbólicas dos pobres urbanos. Teresina: Halley, 2003.

LIMA, Antonia Jesuíta. Favela Cohebe: uma história de luta por habitação popular em Teresiana - PI. $2^{\text {a }}$. ed. Teresina: EDUFPI, 2010.

LORENZETTI, Maria Sílvia Barros. A questão habitacional no Brasil. Brasília: Câmara dos Deputados [Estudo], 2001. Disponível em:

<http://bd.camara.gov.br/bd/handle/bdcamara/1469>, acessado em 16 set. 2014.

MEDEIROS, Manoel Sousa. A redemocratização e às manifestações políticas no bairro Dirceu Arcoverde (1984 a 1985). 2006. Monografia (Curso de História) - Universidade Estadual do Piauí - Campus Clóvis Moura, Teresina, 2006.

MONTE, Regianny Lima, Memória e (res)sentimento em torno do processo de modernização de Teresina durante a década de 1970. In: NASCIMENTO, Francisco Alcides do (Org.). Sentimentos e ressentimentos em cidades brasileiras. Teresina EDUFPI; Imperatriz, MA: Ética, 2010.

MORADORES do Itararé na Câmara Pedindo Mudança. O Estado, Teresina, 03 abr. 1979.

NASCIMENTO, Francisco Alcides do. Cajuína e cristalina: as transformações espaciais vistas pelos cronistas que atuaram nos jornais de Teresina entre 1950 e 1970. Revista Brasileira de História. vol.27 n.53 São Paulo Jan./Jun. 2007.

NASCIMENTO, João Batista Sousa do. Itararé: um olhar histórico e social entre 1976 e 1983. 2005. Monografia (Curso de graduação em História) - Universidade Estadual do Piauí - Campus Clóvis Moura, Teresina, 2005.

NOME de Dirceu Para o Itararé. O Dia, Teresina, 03 abr. 1979, p. 04. 
NORA, Pierre. Entre Memória e História: a problemática dos lugares. Projeto História: Revista do programa de Estudos Pós-Graduados em História do Departamento de História da PUC-SP. V. 10. São Paulo, dezembro, 1993.

OLIVEIRA Maria Salete da Silva. Entrevista a Manoel Sousa Medeiros, em 22 de julho de 2005, In: MEDEIROS, Manoel Sousa. A redemocratização e às manifestações políticas no bairro Dirceu Arcoverde (1984 à 1985). 2005. Monografia (Curso de História) Universidade Estadual do Piauí - Campus Clóvis Moura, Teresina, 2005.

PASAVENTO, Sandra Jatahy. Cidades visíveis, cidades sensíveis, cidades imaginarias.

Revista Brasileira de História, São Paulo. v.17., n. 53, julho de 2007.

PIAUÍ. Mensagem à Assembleia Legislativa. Governador Dirceu Mendes Arcoverde, em 01 de março de 1975. Teresina: Assembleia Legislativa do Piauí, 1975.

POLLAK, Michael. Memória, esquecimento, silêncio. Estudos Históricos, Rio de Janeiro, v. 2, n. 3, 1989.

REMÒND, René. Por uma história presente. In: REMÒND, René (Org.). Por uma história política. Rio de Janeiro: Editora FGV, 1996.

SANTOS, José Lopes dos. Dirceu Arcoverde: missão cumprida. 2 ed. Brasília: Centro Gráfico do Senado Federal. 1982.

SETE mil pedem nome de Dirceu para Itararé. O Dia, Teresina, 03 abr. 1979.

SILVA, Alberto Tavares. Conferência na Associação Comercial Piauiense (06 de julho de 1980). In: SILVA, Alberto Tavares. Minha luta por um Piauí melhor: v.3. Brasília: Centro Gráfico do Senado Federal, 1980.

SILVA, Humberto Coelho. Entrevista concedida a Manoel Sousa Medeiros, em 05 de novembro de 2005. In: MEDEIROS, Manoel Sousa. A redemocratização e às manifestações políticas no bairro Dirceu Arcoverde (1984 à 1985). 2005. Monografia (Curso de História) - Universidade Estadual do Piauí - Campus Clóvis Moura Teresina, 2005 .

SILVA, Laerte Carson Sampaio e. Dirceu: uma história de conquistas (1980-2006). 2008. Monografia (Curso de graduação em História) - UFPI. Departamento de História e Geografia, Teresina, 2008.

SILVA, Maria Neide da. Entrevista concedida a Verônica Viana de Sousa, em 15 out. 2010. In: SOUSA NETO, Marcelo de. De muitos sonhos e poucos tijolos: Conjunto Habitacional 
Dirceu Arcoverde, história e memória (Teresina-PI, 1976-1986). Teresina: Universidade Estadual do Piauí, 2013. Relatório de pesquisa

SILVA, Mariane Vieira da. Nas entrelinhas da história: as primeiras instituições educacionais no cenário urbano do Itararé (1978-1983). 2013. Monografia (curso de Pedagogia) - UFPI, Teresina, 2013.

THOMPSON, Paul. A voz do passado. São Paulo: Paz e Terra, 2002.

VELOSO, Maria Irmani. Entrevista concedida a Manoel Sousa Medeiros, em 27 de setembro de 2005. In: MEDEIROS, Manoel Sousa. A redemocratização e às manifestações políticas no bairro Dirceu Arcoverde (1984 a 1985). 2006. Monografia (Curso de HIstória) - Universidade Estadual do Piauí - Campus Clóvis Moura, Teresina: 2006. 